\title{
MDCT angiography assessment of tetralogy of Fallot with atresic left pulmonary artery
}

\author{
Kantarci $\mathrm{M}^{1}$, Yuce $\mathrm{I}^{1}$, Yalcin $\mathrm{A}^{1}$, Arslan $\mathrm{S}^{2}$, Gundogdu $\mathrm{F}^{2}$ \\ Atatürk University, School of Medicine, Department of Radiology, Erzurum, Turkey. akkanrad@hotmail.com
}

\begin{abstract}
A 24-year-old female patient was admitted to clinic with a 10-year history of dyspnoea. A chest radiograph showed mild cardiomegaly and echocardiography revealed classic findings of Fallot's tetralogy (TOF). Multidetector-computed tomography (MDCT) angiography was performed to evaluate the additional vascular anomalies. MDCT undoubtedly revealed left pulmonary arterial atresia as well as complex intracardiac and vascular anatomic features of TOF. We described both image findings of MDCT angiography for TOF and additional vascular anomalies in this patient (Fig. 3, Ref. 8). Full Text in PDF www.elis.sk.

Key words: tetralogy of Fallot, MDCT, atresia left pulmonary artery.
\end{abstract}

TOF is the most common cause of cyanotic congenital heart disease associated with varying degrees of stenosis of pulmonary arteries. An accurate assessment of the size and anatomy of pulmonary arteries is often difficult with the use of echocardiography and conventional cineangiography (1). For assessment of pulmonary arterial anatomy in patients with TOF, MDCT is superior to echocardiography as it is capable of performing three-dimensional reconstruction (2). MDCT can easily depict the complete pulmonary arterial anatomy which is difficult to evaluate with conventional cardiac imaging techniques. According to our knowledge, our case as of an adult patient with TOF accompanied with left pulmonary artery atresia is the first report in literature revealed by MDCT angiography.

\section{Case report}

In June 2010, a 24-year-old woman with a 10-year history of progressive dyspnoea and chest pain was referred. She had a history of recurrent miscarriages. Physical examination showed normal findings except for cyanotic appearance. Her blood pressure was $122 / 72 \mathrm{mmHg}$; she had a heart rate of 75 beats/min and a regular respiratory rate of 16 breaths/min. Chest radiography showed a mildly enlarged cardiac silhouette and normal pulmonary vascularity. An electrocardiogram showed sinus rhythm, right bundle branch block and right axis deviation. Transthoracic echocardiography revealed an interposition of aortic valve, ventricular septal defect, mild pulmonary stenosis and right ventricular hyper-

${ }^{1}$ Atatürk University, School of Medicine, Department of Radiology, Erzurum, Turkey, and ${ }^{2}$ Atatürk University, School of Medicine, Department of Cardiology, Erzurum, Turkey

Address for correspondence: M. Kantarci, MD, 200 Evler Mah. 14. Sok No 5., Dadaskent, Erzurum, Turkey.

Phone: +90.442. 2361212.1521, Fax: +90.442.2361301

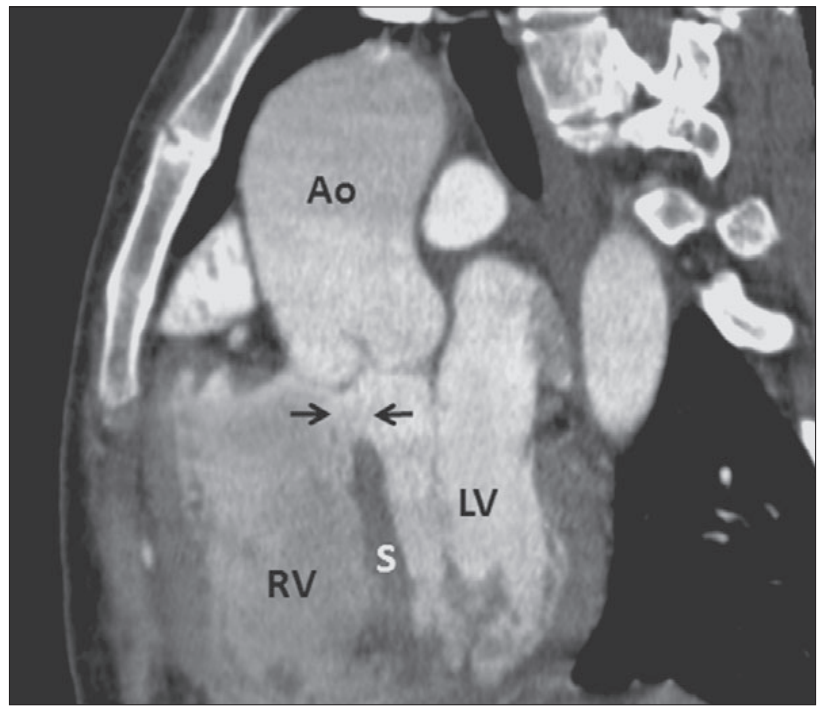

Fig. 1. Lateral oblique MIP view image of the heart shows ventricular septal defect (arrows) and overriding aorta. $S$ - interventricular septum, $L V$ - left ventricle, RV - right ventricle, Ao - aorta.

trophy. To exclude complex vascular anatomy, MDCT angiography was performed on a 16-detector-row CT scanner (Aquillon; Toshiba Medical Systems, Tokyo, Japan). Scans were obtained with $160.5-\mathrm{mm}$ collimation, $1.0-\mathrm{mm}$ slice thickness and $1.0-\mathrm{mm}$ reconstruction interval. Iodinated contrast medium (Omnipaque, Amersham Health, Cork, Ireland) was injected intravenously in amount of $90 \mathrm{ml}$ at $4.5 \mathrm{ml} / \mathrm{s}$ followed by $40 \mathrm{ml}$ saline at $2.5 \mathrm{ml} / \mathrm{s}$. CT scans were obtained from the site $1 \mathrm{~cm}$ below the carina to the diaphragmatic face of the heart during a single breath-holding period with retrospective ECG gating. For image analysis, five data sets were reconstructed at 50, 60, 70, 75 and $80 \%$ of R-R interval. Reconstructed images were then transferred to a process- 

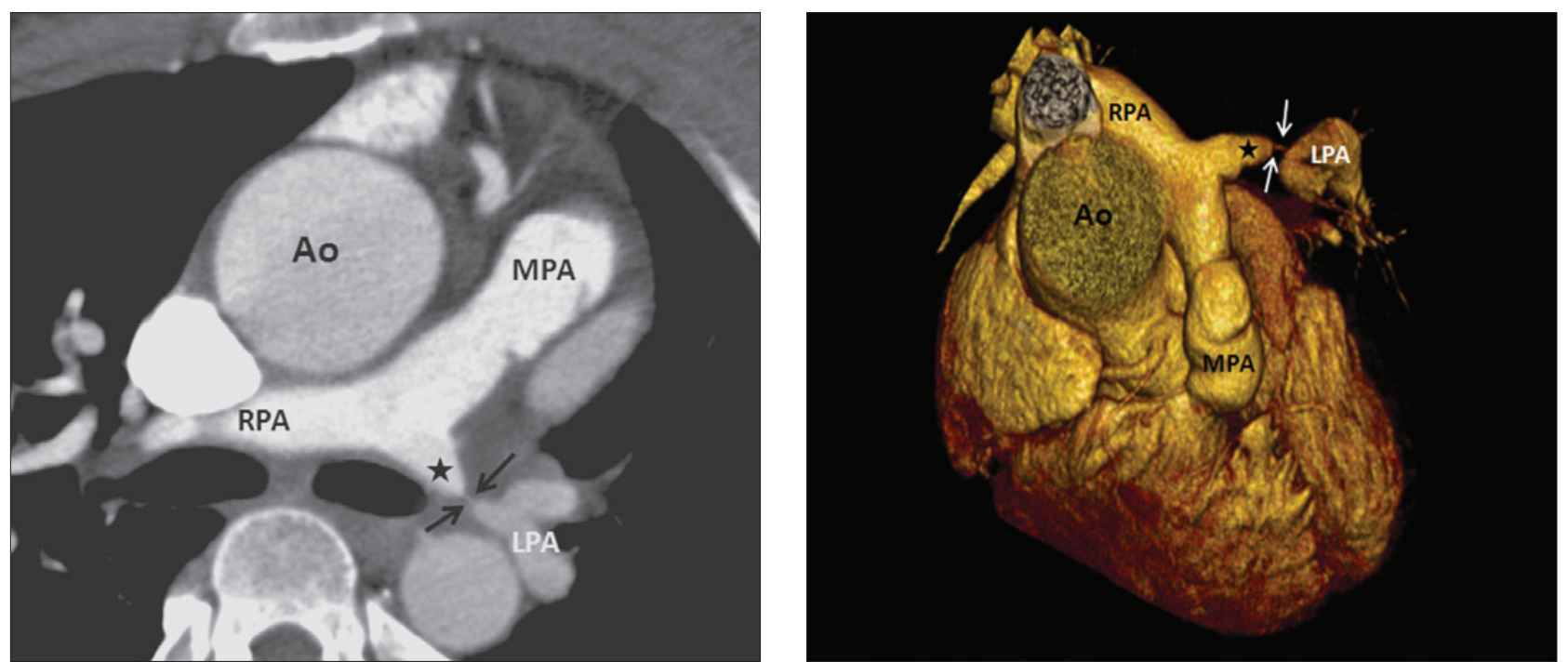

Fig. 2 a, b. Axial image of the heart (a) shows left pulmonary arterial atresia with fibrous band (arrows). Anterior view of 3D volume rendered image (b) shows left pulmonary arterial atresia with fibrous band (arrows). MPA - main pulmonary artery, Ao - aorta, LPA - left pulmonary artery, RPA - right pulmonary artery, * - atresic segment of left pulmonary artery

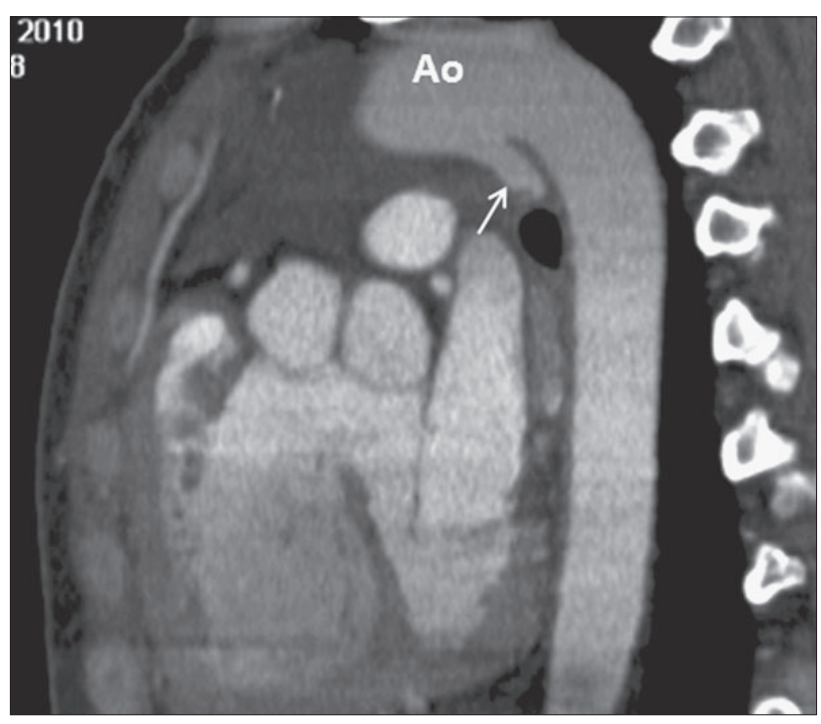

Fig. 3. Sagittal image of the heart shows collateral artery which supplies the left pulmonary artery beyond the atresic segment (arrow). Ao- aorta.

ing workstation for further analysis with specialized software. In addition to the traditional axial images, all the other available techniques (multiplanar reconstructions (MPR), curved multiplanar reformation, sliding thin-slab maximum intensity projection (MIP) and 3D volume rendering (3D VR) images were used for the assessment of the pulmonary arterial anatomy. MDCT clearly showed complex cardiac anatomy in a case with TOF (Fig. 1) and left pulmonary arterial atresia (Fig. 2A, B). The vascular supply beyond the distal segment of atresic segment was being provided by an aberrant pulmonary artery originating from the aortic arch (Fig. 3). Based on these findings, the patient was referred to cardiovascular surgeon.

\section{Discussion}

Tetralogy of Fallot is among the most common cyanotic heart diseases and accounts for approximately $4-8 \%$ of all congenital cardiac lesions. This abnormality results in ventricular septal defect, anterior displacement of the aortic valve, right ventricular outflow tract obstruction, and consequent right ventricular hypertrophy $(3,4)$. Depending on the degree of obstruction of the right ventricular outflow tract, bronchial and aortopulmonary collateral vessels may supply a variable amount of blood to the lungs (1). Tetralogy of Fallot is often associated with various degrees of right ventricular outflow tract (from mild arterial stenosis to a complete absence of the main pulmonary artery or its branches).

The main imaging modalities used in the diagnosis of TOF are conventional angiography and echocardiography. However these techniques may be inadequate in the diagnosis of such complex cardiac pathologies. In our case echocardiography and cardiac catheterization revealed atresic left pulmonary artery despite normal left pulmonary vascular signs in chest $\mathrm{x}$-ray. To explain this paradox, MDCT was performed. With 3D reconstruction of TOF, atresic left pulmonary artery and aberrant artery originating from the aortic arch were identified. The localization and length of the aberrant segment were also shown. Based on data acquired an operation was planned by surgeon.

Several other techniques are used in the diagnosis of such complex cardiac pathologies including echocardiography, selective cardiac catheterization and magnetic resonance imaging. Echocardiography usually remains the primary imaging technique in diagnosis, but its overall anatomic depiction is relatively poor especially outside the heart. To a great extent, the diagnosis depends on the skill and experience of the operator. Selective cardiac catheterization can be used in the diagnosis of TOF with atresic left pulmonary artery however it is an invasive and expensive method 


\section{$732-734$}

requiring hospitalization. In addition only one vascular tracing can be made in one session. Cardiac MRI is also a technique for the evaluation of complex congenital heart disease. Cardiac MR imaging with three-dimensional reconstruction has distinct advantages for pre- or postoperative assessments of pulmonary anatomy in patients with Tetralogy of Fallot and pulmonary atresia (1). It provides a practical method for quantifying the pulmonary regurgitation $(5,6)$. Nevertheless, MR imaging has also its limitations including long acquisition time which may necessitate sedation in young children and may present a problem in the examination of patients with unstable clinical condition.

CT has been used but its clinical applicability has been limited by low temporal resolution of conventional CT. Nevertheless, novel advances in CT technology provide a non-invasive technique offering an accurate diagnostic modality to visualize the cardiac structure in patients with congenital heart disease $(7,8)$. MDCT has its own advantages, specifically high temporal and spatial resolution along with single breath-hold scanning time.

In our case of an adult patient, we depicted the complex anatomy of TOF and accompanied vascular abnormality with great precision. In such cases MDCT not only provides diagnostic information to radiologists but also guides the cardiovascular surgeons.

In conclusion, ECG-gated cardiac MDCT is useful to detect and characterize TOF and accompanied vessel anomalies in children and adult patients.

\section{References}

1. Boechat MI, Ratib O, Williams PL, Gomes AS, Child JS, Allada V. Cardiac MR Imaging and MR Angiography for Assessment of Complex Tetralogy of Fallot and Pulmonary Atresia. RadioGraphics 2005; 25: 1535-1546.

2. Ley S, Zaporozhan J, Arnold R, Eichhorn J, Schenk JP, Ulmer H et al. Preoperative assessment and follow-up of congenital abnormalities of the pulmonary arteries using CT and MRI. Eur Radiol 2007; 17: 151-162.

3. Mirowitz SA, Gutierrez FR, Canter CE, Vannier MW. Tetralogy of Fallot: MR findings. Radiology 1989; 171: 207-212.

4. Van Praagh R, Van Praagh S, Nebesar RA, Muster AJ, Sinha SN, Paul MH. Tetralogy of Fallot: underdevelopment of the pulmonary infundibulum and its sequelae. Am J Cardiol 1970; 26: 25-33.

5. Helbing WA, De Roos A. Clinical applications of cardiac magnetic resonance imaging after repair of tetralogy of Fallot. Pediatr Cardiol 2000; 21: 70-79.

6. Rebergen SA, Ottenkamp J, Doornbos J, van der Wall EE, Chin JG, de Roos A. Postoperative pulmonary flow dynamics after Fontan surgery: assessment with nuclear magnetic resonance velocity mapping. J Am Coll Cardiol 1993; 21: 123-131.

7. Kantarci M, Koplay M, Bayraktutan U, Gundogdu F, Ceviz N. Congenitally corrected transposition of the great arteries: MDCT angiography findings and interpretation of complex coronary anatomy. Int J Cardiovasc Imaging 2007; 23: 405-410.

8. Durur-Subasi, Kantarci M, Durur-Karakaya A, Okur A. Comparison of 16-Slice Computed Tomography with Conventional Angiography to Evaluate Coronary Artery Stent Patency. Eurasian J Med 2009; 41: 4-9.

Received February 22, 2010. Accepted September 20, 2012. 